\title{
Baran-Marszak Maurice, Le p'tit garçon aux trois vies, illustrations de Zlata Baran-Marszak, préface de Serge Klarsfeld
}

\section{Danielle Delmaire}

\section{(2) OpenEdition Journals \\ Édition électronique \\ URL : https://journals.openedition.org/tsafon/2670 \\ DOI : $10.4000 /$ tsafon. 2670 \\ ISSN : 2609-6420 \\ Éditeur}

Association Jean-Marie Delmaire

Édition imprimée

Date de publication : 1 décembre 2019

Pagination : 185-186

ISSN : $1149-6630$

\section{Référence électronique}

Danielle Delmaire, «Baran-Marszak Maurice, Le p'tit garçon aux trois vies, illustrations de Zlata BaranMarszak, préface de Serge Klarsfeld », Tsafon [En ligne], 78 | 2019, mis en ligne le 01 décembre 2019, consulté le 24 juin 2021. URL : http://journals.openedition.org/tsafon/2670 ; DOI : https://doi.org/ $10.4000 /$ tsafon. 2670

Ce document a été généré automatiquement le 24 juin 2021.

Tsafon. Revues d'études juives du Nord 


\title{
Baran-Marszak Maurice, Le p'tit garçon aux trois vies, illustrations de Zlata Baran-Marszak, préface de Serge Klarsfeld
}

\author{
Danielle Delmaire
}

\section{RÉFÉRENCE}

Paris, éditions Pétra, mai 2019, 77 p., $22 €$

1 Dans son enfance et jusqu'à son adolescence, Maurice Baran-Marszak a vécu trois vies, séparées par un drame puis par une rencontre, heureuse mais qui aurait pu être douloureuse.

2 La première vie se déroule à Dunkerque puis à Lille, de sa naissance en 1933 jusqu'au 11 septembre 1942. Cette vie-là est un bonheur. Maurice, fils unique est très aimé de ses parents qui sont des marchands forains, juifs, polonais, arrivés en France peu de temps avant sa naissance. Très occupés par leur métier, ils confient l'entretien de la maison et la garde de leur enfant à Georgette Franchois, une jeune fille de 16 ans, originaire d'un village voisin : Loon-Plage. Quelque peu délurée, Georgette emmène le petit Maurice dans des aventures qui font ses délices. Et puis, il y a la mer où la famille se retrouve le dimanche. Ce bonheur est à peine troublé par la déclaration de guerre mais, à l'été 1940, il faut emménager à Lille car le littoral est très atteint par les combats. Dans la grande ville, les menaces commencent à peser sur les parents mais Georgette, qui est restée à leur service, anime toujours le quotidien.

Puis vient la catastrophe qui verse brutalement Maurice dans sa seconde vie. Le 11 septembre 1942, la maman est raflée avec ses deux enfants : Maurice et Michel qui n'a que quelques mois. Le papa s'est enfui mais il sera à son tour déporté. Sur le quai de la gare où stationne le train qui doit se diriger vers le camp de Malines en Belgique, c'est 
la grande confusion. Des cheminots parviennent à extraire des enfants et des adultes de la déportation tandis que quelques Lillois se faufilent pour emmener hors de la gare des enfants. Ainsi, le bébé Michel est sorti de la gare par une infirmière qui le cachera dans une clinique jusqu'à la fin de la guerre et Maurice est enlevé par Georgette, accourue sur le quai pour retrouver sa patronne.

4 Alors commence la seconde vie. Georgette confie Maurice à ses parents qui résident à Loon-Plage. Malgré l'absence de ses père et mère qui l'attriste, Maurice mène une vie relativement facile tant l'atmosphère du foyer est chaleureuse et tant la vie à la campagne séduit le petit citadin. Il y fait mille découvertes qui l'extasient. La guerre occupe peu son esprit et pourtant elle se termine.

5 Surgit un autre événement qui bouleverse le bien-être de Maurice. Des demoiselles viennent le chercher chez les parents de Georgette. Elles lui présentent son petit frère qu'il avait presqu'oublié. Ce sont elles qui ont caché Michel. Protestantes, elles ont le souci de l'avenir des deux enfants, elles veulent les réunir et les faire élever dans une nouvelle famille juive, par les époux Marszak, sans enfants.

Et démarre la troisième vie de Maurice, chez ce couple aimant, dont le confort financier lui permet d'élever ces deux orphelins.

7 Maurice, né Baran, devenu Baran-Marszak, a déjà raconté son enfance d'enfant juif traqué, caché et devenu orphelin : Histoire d'un enfant caché du Nord. Familles entre amour et silence (1942-1947), Paris, éditions Le Manuscrit, 2014. Il ne s'agit pas ici d'une réédition mais plutôt d'un récit revisité puisqu'il est illustré par Zlata, l'épouse de Maurice. Des détails plus intimes, des anecdotes plus drôles enrichissent les souvenirs de Maurice. Les dessins, souvent naïfs, conviennent parfaitement à des jeunes lecteurs de l'âge de Maurice lorsque celui-ci fut brutalement acheminé vers le quai de la gare où il vit sa maman pour la dernière fois.

8 Et l'on reste confondu par la capacité de résilience de Maurice Baran-Marszak qui, en l'espace d'une journée, plonge d'une vie vers une autre. Chaque fois, il semble occulter la tristesse de l'arrachement à sa mère, à ses sauveteurs pour s'engager, confiant, dans une nouvelle vie.

9 À faire lire à des enfants pour les initier à l'histoire de la Shoah et à celle des enfants juifs cachés, adoucies par les dessins de Zlata. L'enseignant des classes primaires pourrait utiliser le récit facilement. 